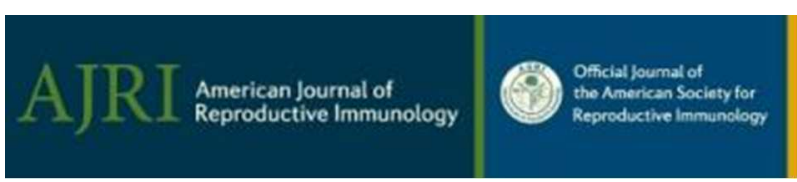

\title{
Localised cyclical variations in immunoproteins in the female genital tract and the implications on the design and assessment of mucosal infection and therapies.
}

\begin{tabular}{|r|l|}
\hline Journal: & American Journal of Reproductive Immunology \\
\hline Manuscript ID & AJRI-07-17-131.R2 \\
\hline Manuscript Type: & Original Manuscript \\
\hline Date Submitted by the Author: & $\mathrm{n}$ /a \\
\hline Complete List of Authors: & $\begin{array}{l}\text { Ekeruche-Makinde, Julia; Imperial College London, Mucosal Infection and } \\
\text { Immunity group, Department of Medicine } \\
\text { Jones, Clifford; Imperial College London, Mucosal Infection and Immunity } \\
\text { group, Department of Medicine } \\
\text { Bartolf, Angela; St George's University of London, St George's vaccine } \\
\text { institute, institute for infection and immunity } \\
\text { Sibeko, Singeziwe; University of Oxford, Nuffield Department of Medicine, } \\
\text { Target Discovery Institute } \\
\text { Baden, Susan; St George's University of London, St George's vaccine } \\
\text { institute, institute for infection and immunity } \\
\text { Cosgrove, Catherine; St George's University of London, St George's } \\
\text { vaccine institute, institute for infection and immunity } \\
\text { Shattock, Robin; Imperial College London, Mucosal Infection and Immunity } \\
\text { group, Department of Medicine }\end{array}$ \\
\hline Keywords: & $\begin{array}{l}\text { Mucosal infection and Immunity, Menstrual cycle, Immunoproteome, } \\
\text { Hormones, HIV, Cervix, Immunoproteins }\end{array}$ \\
\hline
\end{tabular}

\section{SCHOLARONE}

Manuscripts 


\section{Localised cyclical variations in immunoproteins in the female genital tract and the implications on the design and assessment of mucosal infection and therapies.}

Dr Julia Ekeruche-Makinde ${ }^{1}$, Dr Clifford Jones ${ }^{1}$, Dr Angela Bartolf ${ }^{2}$, Dr Singeziwe Sibeko ${ }^{3}$, Ms. Susan Baden ${ }^{2}$, Dr Catherine Cosgrove ${ }^{2}$, Prof Robin John Shattock ${ }^{1}$

${ }^{1}$ Mucosal Infection \& Immunity Group, Division of Infectious Diseases, Department of Medicine, Imperial College London, United Kingdom

${ }^{2}$ St George's Vaccine Institute, Institute for Infection and Immunity, St George's University of London, London, UK

${ }^{3}$ Nuffield Department of Medicine, Target Discovery Institute, University of Oxford, Oxford, UK

\section{Correspondence details}

Name: Julia Ekeruche-Makinde

Address: Department of Medicine, St Mary's Campus, Imperial College London, Norfolk Place W2 1PG. United Kingdom

Fax: $+44(0) 2075942699$

Telephone: $+44(0) 2075942541$

Email: j.makinde@imperial.ac.uk

Running head:

Effects of cyclical mucosal immunological changes

Conflict of interest: The authors declare no conflict of interest 
Abstract

Problem

Fluctuating hormones regulate reproductive processes in the female genital tract.

Consequent changes in the local immunological environment are likely to affect cellular interaction with infectious agents and the assessment of therapies that target mucosal infections.

Method of study

We compared Softcup and Weck-Cel sampling protocols and assessed the changes in the concentrations of 39 soluble proteins with menstrual cycle progression in the mucosal and peripheral compartments.

Results

We demonstrate that the mucosal immunological profile is distinct from serum with inflammatory and migratory signatures that are localised throughout the cycle. The analytes highlighted in the mucosal compartment were generally highest at the follicular phase with a tendency to fall as the cycle progressed through ovulation to the luteal phase.

Conclusion

Our results underscore the need to consider these localised cyclical differences in studies aimed at assessing the outcome of disease and the efficacy of mucosal vaccines and other therapies. 


\section{Introduction}

The female genital mucosa is home to cellular mediators of immunity such as Langerhans cells, $\mathrm{CD} 4^{+}$and $\mathrm{CD} 8^{+}$T cells, macrophages, dendritic cells, neutrophils, NK cells and B cells ${ }^{1}$. These cells mediate the innate and adaptive components of mucosal immunity often via the production of a plethora of chemokines, cytokines and other immunoproteins. CD4+ T cells expressing receptors like CD4 and CCR5 also constitute targets for infectious viral particles that traverse the epithelial barrier ${ }^{2}$. Layers of intact stratified squamous cells line the vagina and ectocervix whilst the single columnar epithelium maintains the integrity of the endometrium and endocervix ${ }^{2}$. Together these cells in the most exposed regions of the female genital tract provide a reasonable physical barrier to the entry of infectious pathogens like HIV and an additional secretory mucosal component containing amongst other things innate antimicrobial proteins like secretory leukocyte protease inhibitor (SLPI) ${ }^{3}$ and defensins $s^{4}$.

Varying levels of endogenous female hormones like oestradiol and progesterone regulate the onset of ovulation, implantation, menstruation and other reproductive processes in the female genital tract ${ }^{5}$. These hormones are also known to induce changes in the appearance and function of mucosal tissue. For instance, over the course of the menstrual cycle hormonal fluctuations are believed to induce changes in the viscosity of the secretory component of the mucosal environment ${ }^{6}$. The epithelial barrier is also reportedly affected by these changes as evidenced in the progesterone induced thinning observed in macaques

${ }^{7}$. These changes have been shown to increase tissue susceptibility to Simian Immunodeficiency Virus (SIV) and are likely to affect HIV infection ${ }^{8}$, as well as the uptake and response to vaccines and topical microbicides. Although absolute numbers of the 
immune cells are believed to fluctuate across the menstrual cycle ${ }^{9}$, phenotypic changes and consequent variations in the levels of secreted chemokines, cytokines and immunoproteins in the periphery and in mucosal tissue have not been fully elucidated. There is some evidence to show that the concentrations of immunoproteins in the mucosal compartment vary with the menstrual cycle ${ }^{10}$. A recent study of cervicovaginal secretions obtained from Tanzanian women considered to be at high risk of HIV demonstrated increases in a number of mucosal analytes from pre- to post-ovulation phases of the menstrual cycle ${ }^{11}$. Such significant variations in the levels of secreted immunoproteins over the menstrual cycle particularly if they are unique to the mucosal compartment are likely to affect the outcome and monitoring of therapies that target the mucosal compartment, thus making a case for the consideration of these differences in the evaluation of mucosal infections in general and in clinical studies aimed at designing or assessing interventions against HIV infection.

Identifying the best sampling approach for evaluating mucosal responses to infection and therapy has been a priority, not only for HIV vaccine development, but also for the evaluation of microbicides ${ }^{12,13}$. Sample quality, ease of collection, processing and downstream analyses are common factors considered in selecting the appropriate approach. In this study we assessed the levels of 39 different soluble immunoproteins in secreted samples collected from the cervicovaginal compartment and compared them with those in the endocervix collected at a single time point corresponding to the follicular phase. In doing so we provide a direct comparison of two important mucosal sampling techniques. We also collected secretions from the cervicovaginal compartment at three distinct points that correspond with the follicular (proliferative), ovulatory and luteal (secretory) phases of the menstrual cycle and compared them with levels seen in the 
1

2

3

4

5

6

7

8

9

10

11

12

13

14

15

16

17

18

19

20

21

22

23

24

25

26

27

28

29

30

31

32

33

34

35

36

37

38

39

40

41

42

43

44

45

46

47

48

49

50

51

52

53

54

55

56

57

58

59

60

peripheral compartment (serum) at the corresponding time points. Analytes assessed

include cytokines, growth factors, chemokines, antimicrobial (including antiviral) proteins

and immunoglobulins. We produced profiles of the immunological landscape across the

menstrual cycle highlighting critical points that need to be considered in designing and assessing mucosal interventions against pathogens like HIV. 


\section{Results}

\section{Characteristics of participants}

Although samples were collected from 31 women during the course of the study, 19 participants were excluded on account of the participants not being available for sampling across all the time points (Figure 1), or not providing matching samples from all sampled compartments for comparison. Of the analysed participants, 4 were on combined oral contraception, one was on combined transdermal contraception whilst the rest of the analysed participants used barrier contraception (condoms). Participants were between the ages of 18 and 45 years with a median age of 27 years.

\section{Endocervical and cervicovaginal compartments display distinctive immunological analyte} signatures in the follicular phase of the menstrual cycle

Samples were collected from two compartments at visit 1 corresponding to days 5-10 of the menstrual cycle from study participants. We measured the concentrations of 39 analytes in the samples collected from the cervical os representing endocervical secretions or the upper vaginal region using Weck-Cel ${ }^{\circledR}$ spears or an Instead ${ }^{\circledR}$ Softcup respectively. We found the analyte signatures to be similar overall (Figure 2A) with strong correlations $(r=0.96 ; p=$ 0.0001) (Figure 2B). However, there were significant differences between the two compartments with regards to a few analytes. Although the average analyte concentrations were generally higher in the vaginal samples we observed significantly higher concentrations in $6 / 39$ analytes (IL-6, $p=0.0137 ;$ IFN- $\beta, p=0.0005 ;$ SLPI, $p=0.0005 ;$ MIP-3 $\alpha$, $p=0.0010 ;$ P-Selectin, $=0.0005 ;$ and $G-C S F, p=0.0244)$ in the samples collected by direct adsorption from the cervical os with Weck-Cel ${ }^{\circledR}$ spears (Supplementary Table 1). Notably 
there were no significant differences in the concentrations of mucosal antibodies (IgG1-4, $\lg A$ or $\lg M)$ recorded using both sampling techniques. Due to the observed correlation between the analyte signatures obtained using both techniques we opted to use Softcups in subsequent analysis as it was generally considered to be more acceptable and less invasive for study participants.

\section{Serum and cervicovaginal compartments display distinctive immunological analyte signatures across the menstrual cycle}

We compared analyte concentrations in the samples obtained from the upper vaginal region with those seen in the serum compartment and found the signature of each compartment to be distinct at visit 1 (Figure 3 and Table 1). The differences in analyte concentrations in both compartments were significant for 29/39 analytes at visit 1 (Table 1). Of the 29 analytes that were found to be different 14 analytes (IL-6, IL-1 $\alpha$, IL-1 $1 \beta$, IL-10, IL-2, $\beta$-defensin 3, Elafin, Hnp 1-3, IL-8, MIP-3 $\alpha$, IP-10, P-Selectin, G-CSF, and TGF- $\beta$ ) were higher in the mucosal compartment whilst 15 analytes (IL-12, IL-4, IL-15, IFN- $\beta$, SLPI, MCP-2, RANTES, L-Selectin, GM-CSF, IgG1, IgG2, IgG3, IgG4, IgA and $\lg M)$ were higher in the serum compartment. We observed similar differences in compartmental analyte signature was seen at visits 2 and 3 (Supplementary Figure $1 \mathrm{~A}-\mathrm{C}$ ). We then sought to determine how the unique signatures identified in the serum and vaginal compartments varied throughout the menstrual cycle. Overall we recorded more significant fluctuations in the concentrations of secreted analytes in the vaginal compartment across the menstrual cycle compared to the serum compartment where analyte concentrations appeared to vary less. Specifically we

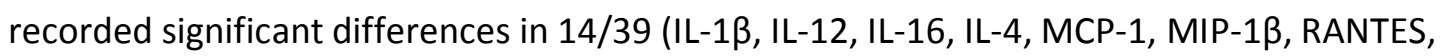
SDF-1ß, L-Selectin, $\lg G 1, \lg G 2$, $\lg G 3$, IgG4, and $\lg M$ ) analytes sampled in the cervicovaginal 
compartment (Figure 4 and Supplementary Figure 2) and found that the concentrations of these analytes decreased across the menstrual cycle phases represented by the three time points that we sampled (i.e. decreased with progression from visits 1 to 3 ). The functional analyte groups highlighted by this trend included chemokines and antibody isotypes even though changes were recorded for analytes belonging to at least three other functional groups. Interestingly the concentrations of secreted analytes in the vagina appeared to be stable between the ovulation and luteal phases.

We recorded significant differences in just 3/39 (SLPI, P-Selectin, and IL-7) analytes in the serum compartment (Figure 4 and Supplementary Figure 2) across the menstrual cycle with all but IL-7 increasing with cycle progression. Fluctuations in serum analyte concentrations across the cycle were significant for analytes belonging to three functional groups (Haemopoietic/growth factors, antimicrobial and cell homing). Immunoglobulin levels remained largely stable in the serum compartment throughout the cycle. Notably there was no overlap between the analytes that were seen to vary across the menstrual cycle in the serum and vaginal compartments (Supplementary Figure 2). 


\section{Discussion}

Our study demonstrates that significant differences exist between the genital immunological secretome and the periphery throughout the menstrual cycle by producing profiles for 39 analytes that are relevant to the investigation of mucosal infections and the evaluation of vaccine responses ${ }^{14,15}$ at three key points of the menstrual cycle. This knowledge is critical because the mucosal environment remains a key route of acquisition and transmission for pathogens like $\mathrm{HIV}^{2}$. The presence of strong local innate and adaptive mucosal immune responses is thought to be important for effective prevention and control of HIV infection ${ }^{16,17}$. It is also crucial to establish a baseline profile for these responses against which any intervention that targets infectious pathogens can be gauged.

Our assessment of two mucosal sampling techniques show a direct correlation in the results obtained. Absorbent sampling materials like Weck-Cel ${ }^{\circledR}$ or ophthalmic sponges/swabs are purportedly advantageous over cervicovaginal lavage (CVL) sampling methods that require sample dilution at the point of collection ${ }^{14}$. However both methods are not necessarily optimal for volume standardisation and ease of sample collection. In studies comparing sampling of mucosal secretions using swabs or CVL, the latter resulted in higher concentrations of immunoproteins despite the extensive dilution of samples that occurred during CVL sample collection ${ }^{13}$. Another study looking at cell recoveries for mucosal sampling techniques noted that the CVL approach enabled the recovery of the lowest amount of viable mononuclear leukocytes in comparison with collection with cytobrushes or biopsies ${ }^{18}$. Softcups rank high in user acceptability ${ }^{12}$ and have become increasingly popular due to the practical advantages of their use by study participants without the need for 
clinical personnel, and possibility of obtaining cervicovaginal secretions as a concentrate without dilution leading to better detection of analytes in comparison with $\mathrm{CVL}^{14}$. We sought to determine whether differences exist in the secreted analyte signatures observed using two sampling methodologies that have not been compared directly before. Whereas previous studies have highlighted the need to consider differences that may arise as a result of methodology or the location of sampling in the genital tract ${ }^{13,14,19}$ we found strong correlations between the secreted analyte signatures observed in samples collected and eluted from Weck-Cel ${ }^{\circledR}$ sponges and those collected using Softcups. However analyte concentrations were distinctly higher in the samples collected using the Softcups. The latter observation is in agreement with a previous study comparing Softcups with CVL sampling ${ }^{14}$. This combined with the higher acceptability of self-sampling provided the rationale for using Softcups for the rest of this study. The notable exceptions to this observation (IL-6, IFN- $\beta$, SLPI, MIP-3 $\alpha$, P-Selectin and G-CSF) may reflect some effect of the different sampling methodology, or actual differences in the quantities of secreted analytes at various sites in genital tract that need to be taken into account when either technique is being utilised. Differences in administration of the sampling techniques used in this study mean that the Weck-Cel ${ }^{\circledR}$ sponges would have absorbed secretions around the cervical os, whilst the insertion of the Softcup in the vaginal would facilitate the collection of samples from several regions of the cervicovaginal tract.

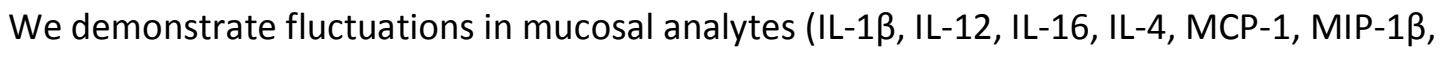
RANTES, SDF-1 $\beta$ and L-Selectin) across the time points that were examined in this study. Evaluation of the functional associations of the analytes that fluctuated significantly across the menstrual cycle in the reproductive compartment revealed the prominence of cellular
\end{abstract}


chemoattractants and proteins associated with the migration of hematopoietic cells. These factors have been shown to target a range of immune cell types including $\mathrm{CD} 4^{+} \mathrm{T}$ cells, NK cells, B cells and monocytes ${ }^{20-23}$. Changes in mucosal immunoglobulins and in proteins associated with the modulation of the inflammatory response (IL-1 $\beta)^{24}$ and the release of inflammatory cytokines (IL-12) ${ }^{25,26}$ were also demonstrated. The analytes highlighted by this study in the mucosal compartment were generally highest at the follicular phase (visit 1) with a tendency to fall as the cycle progressed through ovulation (visit 2) to the luteal phase (visit 3). A study by Francis et al that examined the changes in analyte concentrations preand post-ovulation also revealed a menstrual cycle phase signature in which the concentrations of chemoattractants like MCP-1 and SDF-1 $\beta$ decreased as the cycle progressed beyond ovulation whilst IL-18, IL-10, IL-17 and TGF- $\beta$ increased. Consistent with our data and those of others ${ }^{27,28}$, they also saw a fall in the concentration of mucosal immunoglobulins ${ }^{11}$

Endometrial function and the menstrual cycle is tightly regulated by hormones such as oestrogen and progesterone to ensure the sustenance of progeny. Progesterone increases soon after ovulation resulting in the beginning of what is generally known as the secretory phase of the menstrual cycle where it prepares for the reception of a fertilised egg. This release peaks around day 22 after which progesterone withdrawal occurs as a result of the disintegration of the corpus luteum ${ }^{5}$. Mouse experiments and in vitro studies using human cells show that the withdrawal of the anti-inflammatory effect of progesterone in the follicular phase results in an increase in inflammatory analytes under the direct control of NF-KB 2930,31 and a steady rise in the population of mucosal leucocyte ${ }^{32}$ and antigen presenting cells ${ }^{33}$. In addition to higher levels of inflammatory markers we found evidence 
of high levels of analytes that direct the influx of immune cells in mucosal samples obtained in the follicular phase (visit 1). This very specific signature appeared to be localised and conspicuously absent in the peripheral compartment where we recorded significant changes for just three analytes (IL-7, P-Selectin and SLPI). Although distinct from the mucosal compartment, the changes seen in the periphery could be significant in so much as they indicate the initiation of immune cell homeostasis, migration to mucosal sites and priming for any infection as a result of rising levels of inflammation. ${ }^{34} 35,36$. The inflammatory and migratory signature seen in the mucosal compartment was significantly reduced by visit 2 which coincides with ovulation and rising levels of progesterone in the mucosal compartment.

These findings can inform our understanding of mucosal infections and the approach to evaluating interventions. For example, a localised surge in mucosal inflammation and migratory signals in the follicular phase may create an enabling environment for HIV entry into susceptible cells that have migrated into the mucosal environment ${ }^{2,37}$ and found their way into its secretions ${ }^{18}$. A number of the analytes that were highlighted in our results have been implicated in the provision of migratory stimulus to antigen presenting cells ${ }^{38}$, including lymphocytes which are capable of viral uptake and the presentation of HIV antigens ${ }^{2}$. An influx of antigen presenting cells (APCs) in response to these migratory and inflammatory or danger signals in the late luteal and follicular ${ }^{33}$ phase may result in the uptake of virus upon exposure and the subsequent migration of APCs to the draining lymph nodes where further dissemination can occur ${ }^{2}$. Targeting of mucosal vaccines to the late luteal or follicular phase for instance may enhance their uptake or efficacy. 
In this study we have measured 39 analytes to provide a picture of how they vary in the mucosal versus peripheral compartment and across the menstrual cycle. In doing so we also provide a comparison of key mucosal sampling methods to inform therapeutic research. The limitations of this study includes the small sample size and the absence of a direct quantification of hormone levels in study participants. However we reasoned that samples collected at visits 1 and 3 in normal cycling women would enable us to compare the immunological profiles at the peak of oestrogen and progesterone release, respectively. In addition we have not adjusted our findings to reflect any difference that may arise from reported behaviours described in the methods section such as the use of oral contraception, or unreported/undiagnosed infections in volunteers. It is also worth pointing out that four of the participants in this study were on oral combined contraception whilst one was on combined transdermal contraception even though they all had regular withdrawal bleeding.

Nevertheless our data highlight the need to standardise the timing of mucosal sampling in clinical studies. One approach could be to ensure that sampling in all study participants occurs within a similar period of the menstrual cycle to ensure that the differences in local cyclical effects are minimised. A similar advantage would be applicable if the administration and assessment of therapies are designed to fall within similar periods within the menstrual cycle. As an example, the period defined by visits $2-3$ of our study showed the least amount variation in analyte concentrations (Figure 4), presenting a relatively long window to accommodate the challenges of scheduling of volunteer visits for clinical studies. Where practically possible, studies could also be designed to target this period, or other periods of the cycle. 
There is currently a need to design and evaluate vaccines that are capable of eliciting protective mucosal immunological responses that can prevent HIV acquisition and transmission ${ }^{39-41}$, particularly in women ${ }^{2}$ who have been reported to be more susceptible to infection compared to age-matched males ${ }^{42}$. Indeed a number of studies have evaluated aspects of this approach such as the linkage between the nasal and genital mucosal compartments ${ }^{43}$, and the quality of the responses that are elicited by various antigens and delivery methods ${ }^{44,45}$. None of these studies have taken into account the role that the unique and dynamic cervicovaginal immunological landscape might have on the outcome of vaccine regimens. Our data demonstrates the need to fully consider this in the design and execution of future vaccine studies. 


\section{Methods}

\section{Study design and ethical approval}

The CASHIR (Characterisation of the activity and stability of anti-HIV-1 agents in the presence of female genital secretions and establishing methods to measure immune response) study was initiated to help in the development of novel agents against mucosal infections such as HIV. Its main aim was to provide some clarity on reliable methods used to measure immune responses in the female genital tract. As such it was designed as a longitudinal prospective cohort study to enable the standardization and comparison of methods and sampling approaches. We set out to explore the measurement of cytokine, chemokine and antibody responses in cervical/vaginal secretions and serum, taking into cognisance the effect of the menstrual cycle on these factors. Samples were collected at The Vaccine Institute, St George's University of London. All volunteers gave full informed and written consent. All relevant approvals were in place and the study was conducted in accordance with the relevant Clinical Regulations and guidelines on Good Clinical Practice.

\section{Subjects and sample collection protocol}

Screening was focused on healthy female volunteers aged $18-45$ years who were HIV negative, recruited through the use of staff and student mail shots and through the placement of posters within the campuses of St George's University of London and St George's Foundation Trust Hospital notice boards. Volunteers were questioned by a doctor or trained research nurse for any history of sexually transmitted infections like HIV and administered with a pregnancy test. Exclusion criteria were set out as a) Inability to consent b) women who were actively menstruating c) women who have had unprotected (condoms) sexual intercourse 24 hours prior to sample collection, d) women who had intrauterine 
contraceptive device in situ e) ability to communicate effectively with clinical team. In addition, participants who developed bacterial vaginosis, thrush or went on antibiotics were made to wait until the next cycle for collection with repeats to first sample collection initiated where necessary. Screened women were eligible to participate if they had regular menstrual cycles of 28-day duration on average. Samples were collected during three scheduled visits coinciding with days 5-10 (end of menstruation; follicular phase), days 1416 (ovulation), and days 19-24 (luteal phase) of the menstrual cycle. Day 1 coincided with the first day of their menses.

Serum was collected for antibody and analyte screening at all three visits. Briefly, $10 \mathrm{ml}$ of peripheral blood was centrifuged in sterile collection tubes for ten minutes at $400 \times g$ to obtain serum. Serum samples were immediately stored at $\leq-15^{\circ} \mathrm{C}$ in $500 \mu \mathrm{l}$ aliquots. Cervicovaginal secretions were collected by study participants at all three visits using INSTEAD Softcup ${ }^{\circledR}$ (Evofem Inc). The Softcup was self-inserted into the upper vaginal region and left in situ for one hour before being placed in a sterile $50 \mathrm{ml}$ collection container (Beckton Dickinson, UK) for immediate storage at $-80{ }^{\circ} \mathrm{C}$ prior to analysis. For analysis, volumes of samples were measured using a positive displacement pipette and diluted in extraction buffer [ $250 \mathrm{mM} \mathrm{NaCl}, 1 \times$ protease inhibitor cocktail set 1 (Calbiochem) in phosphate buffered saline (1XDPBS, Gibco)] prior measuring analyte concentrations by Luminex. Additional endocervical secretion samples were collected from volunteers at visit 1 (corresponding to days 5-10 of the menstrual cycle and at the same time that corresponding CVS was collected) under speculum examination using a Weck-Cel ${ }^{\circledR}$ ophthalmic sponge. Two sponges were placed in the cervical os for 1 minute each to passively absorb cervical secretions. After removal the Weck-Cels ${ }^{\circledR}$ were immediately 
transferred into $\operatorname{Costar}^{\circledR}$ Spin- $X^{\circledR}$ polypropylene microcentrifuge filter tubes (Corning Inc) containing extraction buffer and stored at -80 until analysis.

\section{Processing of samples for Immunological assays}

Prior to immunological analysis serum sample aliquots were heat inactivated at $56{ }^{\circ} \mathrm{C}$ with slow mixing for 35 minutes. Softcups containing secretions in $50 \mathrm{ml}$ collection tubes were removed from $-80^{\circ} \mathrm{C}$, allowed to thaw on ice, and centrifuged at $400 \times g$ for 15 minutes at 4 ${ }^{\circ} \mathrm{C}$. An equal volume of extraction buffer was then added to the secretion samples (after removal of the cup) with mixing. Processed aliquots were then used in immunological assays or frozen at $-80^{\circ} \mathrm{C}$. Similarly Spin-X tubes containing Weck-Cel ${ }^{\circledR}$ spears (sponges) were thawed on ice, centrifuged at $13,000 \mathrm{rpm}$ in a micro-centrifuge at $4{ }^{\circ} \mathrm{C} .300 \mu \mathrm{l}$ extraction buffer was added to the top chamber of the Spin-X tube containing the spears centrifuged again for an additional 15 minutes at $13,000 \mathrm{rpm}$ and $4{ }^{\circ} \mathrm{C}$ to further extract any residual secretions. Sponges were removed and eluates used in assays or aliquoted for storage at $80^{\circ} \mathrm{C}$.

\section{Measurement of Immunological proteins}

Thirty-three soluble immune proteins were quantified in all processed samples using an inhouse Luminex assay comprising of four panels. The proteins analysed were as follows;

Panel 1- IL-7, IL-6, G-CSF, MIP-3 $\alpha$, IL-8, MCP-1. Panel 2- GM-CSF, IP-10, IL-12, MIG, IL-16, IL2, RANTES, MCP-2, IL-4, MIP-1 $\beta$, IL-1 $\alpha$, SDF-1, IFN- - , IFN- $\beta$, TGF $\beta$, IL-1 $\beta$, IL-15, TNF $\alpha$. Panel 3-

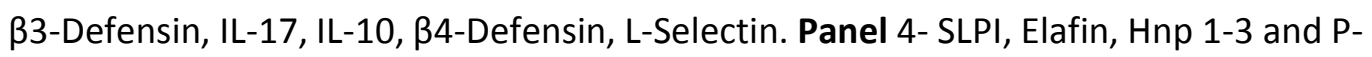
Selectin. Additionally, six immunoglobulin (Ig) isotypes (IgG1, IgG2, IgG3, IgG4, IgA, IgM) were measured using a Bio-Plex Pro Human Isotyping 6-plex panel kit from Bio-rad 
Laboratories, In all cases, a set of standard curves were run on each plate. UK according the manufacturer's instructions. Analytes were quantified using Bio-Plex ${ }^{\circledR} 100$ Luminex analyzer (Bio-rad Laboratories). Data was collected for three replicates per sample using Bio-Plex Manager Software version 6. A five parameter logistic regression formula was used to derive sample concentrations from the standard curves. Analytes below the lower limit of detection were assigned a concentration of half the lower limit of quantification (LLOQ).

\section{Statistical analysis}

Data was characterised using a range of statistical methods. We did not assume a normal distribution for analyte concentrations in our population. The comparison of analyte concentrations in paired samples collected from various compartments was performed using the non-parametric Wilcoxon matched-pairs signed ranked test. The same method was applied to the evaluation of analyte fluctuations in each compartment over the menstrual cycle. Spearman correlation was used to calculate the relationships between analyte sampling techniques and compartmental secretions. p-values were generally considered not significant at $\geq 0.05$. All statistical analyses were performed and graphs drawn using Graphpad Prism 6 Software. 
1

2

3

4

5

6

7

8

9

10

11

12

13

14

15

16

17

18

19

20

21

22

23

24

25

26

27

28

29

30

31

32

33

34

35

36

37

38

39

40

41

42

43

44

45

46

47

48

49

50

51

52

53

54

55

56

57

58

59

60

Acknowledgements: We thank the donors and clinical staff at the Centre for Infection, St George's, University of London, United Kingdom. This work was supported by funds from the EU Commission FP7 MOTIF (Microbicide Optimisation through Innovative Formulation for prevention of mucosal HIV Infection) grant (Ref 305316)

Author contributions: JE-M, CJ and SS ran all experiments and sample analysis. AB, SB and CAC provided clinical direction for sample collection and processing. RJS provided scientific direction and support throughout the study. 


\section{References}

1. Reis Machado, J. et al. Mucosal immunity in the female genital tract, HIV/AIDS. BioMed research international, 350195 (2014).

2. Shattock, R.J. \& Moore, J.P. Inhibiting sexual transmission of HIV-1 infection. Nature reviews. Microbiology 1, 25-34 (2003).

3. Moriyama, A. et al. Secretory leukocyte protease inhibitor (SLPI) concentrations in cervical mucus of women with normal menstrual cycle. Molecular human reproduction 5, 656-661 (1999).

4. Meng, W., Du, R., Wang, Y., Chen, Z. \& Ding, Y. Human beta-defensin messenger RNA is overexpressed in the cervical epithelia of patients with nongonococcal cervicitis. Journal of lower genital tract disease 17, 440-445 (2013).

5. Maybin, J.A. \& Critchley, H.O. Menstrual physiology: implications for endometrial pathology and beyond. Hum Reprod Update 21, 748-761 (2015).

6. Birse, K. et al. Molecular Signatures of Immune Activation and Epithelial Barrier Remodeling Are Enhanced during the Luteal Phase of the Menstrual Cycle: Implications for HIV Susceptibility. Journal of virology 89, 8793-8805 (2015).

7. Kersh, E.N. et al. SHIV susceptibility changes during the menstrual cycle of pigtail macaques. Journal of medical primatology 43, 310-316 (2014).

8. Saba, E. et al. Productive HIV-1 infection of human cervical tissue ex vivo is associated with the secretory phase of the menstrual cycle. Mucosal immunology 6 , 1081-1090 (2013).

9. Northern, A.L., Rutter, S.M. \& Peterson, C.M. Cyclic changes in the concentrations of peripheral blood immune cells during the normal menstrual cycle. Proc Soc Exp Biol Med 207, 81-88 (1994). 
10. Al-Harthi, L. et al. A menstrual cycle pattern for cytokine levels exists in HIV-positive women: implication for HIV vaginal and plasma shedding. AIDS 15, 1535-1543 (2001).

11. Francis, S.C. et al. Immune Activation in the Female Genital Tract: Expression Profiles of Soluble Proteins in Women at High Risk for HIV Infection. PloS one 11, e0143109 (2016).

12. Jaumdally, S.Z. et al. Comparison of sampling methods to measure HIV RNA viral load in female genital tract secretions. Am J Reprod Immunol 77 (2017).

13. Dezzutti, C.S. et al. Performance of swabs, lavage, and diluents to quantify biomarkers of female genital tract soluble mucosal mediators. PloS one 6, e23136 (2011).

14. Archary, D. et al. Randomized Cross-Sectional Study to Compare HIV-1 Specific Antibody and Cytokine Concentrations in Female Genital Secretions Obtained by Menstrual Cup and Cervicovaginal Lavage. PloS one 10, e0131906 (2015).

15. Arnold, K.B. et al. Increased levels of inflammatory cytokines in the female reproductive tract are associated with altered expression of proteases, mucosal barrier proteins, and an influx of HIV-susceptible target cells. Mucosal immunology 9 , 194-205 (2015).

16. Broliden, K. Innate molecular and anatomic mucosal barriers against HIV infection in the genital tract of HIV-exposed seronegative individuals. The Journal of infectious diseases 202 Suppl 3, S351-355 (2010).

17. Lajoie, J. et al. A distinct cytokine and chemokine profile at the genital mucosa is associated with HIV-1 protection among HIV-exposed seronegative commercial sex workers. Mucosal immunology 5, 277-287 (2012). 
18. McKinnon, L.R. et al. Optimizing viable leukocyte sampling from the female genital tract for clinical trials: an international multi-site study. PloS one 9, e85675 (2014).

19. Birse, K.M. et al. Unbiased proteomics analysis demonstrates significant variability in mucosal immune factor expression depending on the site and method of collection. PloS one 8, e79505 (2013).

20. Skundric, D.S., Cruikshank, W.W. \& Drulovic, J. Role of IL-16 in CD4+ T cell-mediated regulation of relapsing multiple sclerosis. J Neuroinflammation 12, 78 (2015).

21. Brown, M.A. IL-4 production by T cells: you need a little to get a lot. J Immunol 181, 2941-2942 (2008).

22. Menten, P. et al. Role of the autocrine chemokines MIP-1alpha and MIP-1beta in the metastatic behavior of murine T cell lymphoma. J Leukoc Biol 72, 780-789 (2002).

23. Lau, T.T. \& Wang, D.A. Stromal cell-derived factor-1 (SDF-1): homing factor for engineered regenerative medicine. Expert Opin Biol Ther 11, 189-197 (2011).

24. Dinarello, C.A. Immunological and inflammatory functions of the interleukin-1 family. Annu Rev Immunol 27, 519-550 (2009).

25. Trinchieri, G., Pflanz, S. \& Kastelein, R.A. The IL-12 family of heterodimeric cytokines: new players in the regulation of T cell responses. Immunity 19, 641-644 (2003).

26. Trinchieri, G. Interleukin-12 and the regulation of innate resistance and adaptive immunity. Nat Rev Immunol 3, 133-146 (2003).

27. Usala, S.J., Usala, F.O., Haciski, R., Holt, J.A. \& Schumacher, G.F. IgG and IgA content of vaginal fluid during the menstrual cycle. The Journal of reproductive medicine $\mathbf{3 4}$, 292-294 (1989). 
28. Lu, F.X. et al. Immunoglobulin concentrations and antigen-specific antibody levels in cervicovaginal lavages of rhesus macaques are influenced by the stage of the menstrual cycle. Infect Immun 67, 6321-6328 (1999).

29. Jabbour, H.N., Kelly, R.W., Fraser, H.M. \& Critchley, H.O. Endocrine regulation of menstruation. Endocr Rev 27, 17-46 (2006).

30. Evans, J. \& Salamonsen, L.A. Decidualized human endometrial stromal cells are sensors of hormone withdrawal in the menstrual inflammatory cascade. Biol Reprod 90, 14 (2013).

31. Xu, X. et al. Cyclooxygenase-2 regulated by the nuclear factor-kappaB pathway plays an important role in endometrial breakdown in a female mouse menstrual-like model. Endocrinology 154, 2900-2911 (2013).

32. Salamonsen, L.A. \& Lathbury, L.J. Endometrial leukocytes and menstruation. Hum Reprod Update 6, 16-27 (2000).

33. Thiruchelvam, U., Dransfield, I., Saunders, P.T. \& Critchley, H.O. The importance of the macrophage within the human endometrium. J Leukoc Biol 93, 217-225 (2012).

34. ElKassar, N. \& Gress, R.E. An overview of IL-7 biology and its use in immunotherapy. J Immunotoxicol 7, 1-7 (2009).

35. Moore, K.L. Structure and function of P-selectin glycoprotein ligand-1. Leuk Lymphoma 29, 1-15 (1998).

36. Skott, P., Lucht, E., Ehnlund, M. \& Bjorling, E. Inhibitory function of secretory leukocyte proteinase inhibitor (SLPI) in human saliva is HIV-1 specific and varies with virus tropism. Oral Dis 8, 160-167 (2002). 
37. Devito, C. et al. Mucosal and plasma IgA from HIV-1-exposed uninfected individuals inhibit HIV-1 transcytosis across human epithelial cells. J Immunol 165, 5170-5176 (2000).

38. Arango Duque, G. \& Descoteaux, A. Macrophage cytokines: involvement in immunity and infectious diseases. Front Immunol 5, 491 (2014).

39. Belyakov, I.M., Ahlers, J.D. \& Berzofsky, J.A. Mucosal AIDS vaccines: current status and future directions. Expert Rev Vaccines 3, S65-73 (2004).

40. Belyakov, I.M. \& Berzofsky, J.A. Immunobiology of mucosal HIV infection and the basis for development of a new generation of mucosal AIDS vaccines. Immunity 20, $247-253$ (2004).

41. Tuero, I. \& Robert-Guroff, M. Challenges in mucosal HIV vaccine development: lessons from non-human primate models. Viruses 6, 3129-3158 (2014).

42. UNAIDS Report on the global AIDS epidemic. (2013).

43. Arias, M.A. et al. Glucopyranosyl Lipid Adjuvant (GLA), a Synthetic TLR4 agonist, promotes potent systemic and mucosal responses to intranasal immunization with HIVgp140. PloS one 7, e41144 (2012).

44. Cosgrove, C.A. et al. Comparative Immunogenicity of HIV-1 gp140 Vaccine Delivered by Parenteral, and Mucosal Routes in Female Volunteers; MUCOVAC2, A Randomized Two Centre Study. PloS one 11, e0152038 (2016).

45. Bolton, D.L., Song, K., Tomaras, G.D., Rao, S. \& Roederer, M. Unique cellular and humoral immunogenicity profiles generated by aerosol, intranasal, or parenteral vaccination in rhesus macaques. Vaccine 35, 639-646 (2017). 
Table 1: Median analyte concentrations in the peripheral (serum) and mucosal (cervicovaginal) compartments in the follicular phase of the menstrual cycle

\begin{tabular}{|c|c|c|c|c|c|}
\hline $\begin{array}{l}\text { Functional } \\
\text { classification }\end{array}$ & Analyte & Unit & $\begin{array}{l}\text { Cervicovaginal region } \\
\text { (Softcup) }\end{array}$ & Serum & $p$ value \\
\hline & & & median (range) & median (range) & \\
\hline \multirow{7}{*}{ Pro-inflammatory } & IL-6 & $\mathrm{pg} / \mathrm{ml}$ & $351.7(2.0-2300)$ & $17.3(2.0-36.7)$ & 0.0098 \\
\hline & IL-1 $\alpha$ & $\mathrm{pg} / \mathrm{ml}$ & $1023.3(556.7-11943.3)$ & $4.0(1.0-10.3)$ & 0.0010 \\
\hline & IL-1ß & $\mathrm{pg} / \mathrm{ml}$ & $323.3(123.3-3300)$ & $30.0(4.0-43.3)$ & 0.0010 \\
\hline & IL-12 & $\mathrm{pg} / \mathrm{ml}$ & $4.7(2.0-20)$ & $36.7(19.3-60.0)$ & 0.0010 \\
\hline & IL-16 & $\mathrm{pg} / \mathrm{ml}$ & $56.7(17-10683.3)$ & $205.0(205.0-231.0)$ & 0.3496 \\
\hline & IL-17 & $\mathrm{pg} / \mathrm{ml}$ & $35.0(35.0-196.7)$ & $164.0(17.0-164.0)$ & 0.5449 \\
\hline & TNF- $\alpha$ & $\mathrm{pg} / \mathrm{ml}$ & $2.0(2.0-73.3)$ & $17.3(2.0-26.7)$ & 0.0996 \\
\hline Anti-inflammatory & IL-10 & $\mathrm{pg} / \mathrm{ml}$ & $133.0(6.0-244.0)$ & $66.0(22.0-98.0)$ & 0.0371 \\
\hline \multirow{4}{*}{ Adaptive } & IL-2 & $\mathrm{pg} / \mathrm{ml}$ & $146.7(20.0-356.7)$ & $22.0(22.0-151.33)$ & 0.0049 \\
\hline & IL-4 & $\mathrm{pg} / \mathrm{ml}$ & $44.0(20.0-280.0)$ & $515.7(57.0-913.3)$ & 0.0010 \\
\hline & $\mathrm{IL}-15$ & $\mathrm{pg} / \mathrm{ml}$ & $1.0(1.0-1.0)$ & $4.0(1.0-10.7)$ & 0.0313 \\
\hline & IFN- $\gamma$ & $\mathrm{pg} / \mathrm{ml}$ & $19.0(17.0-110.0)$ & $18.7(3.0-86.7)$ & 0.3096 \\
\hline \multirow{6}{*}{ Antimicrobial } & IFN- $\beta$ & $\mathrm{pg} / \mathrm{ml}$ & $1.0(0.3-10.0)$ & $100.7(16.0-233.3)$ & 0.0010 \\
\hline & ß-defensin 3 & $\mathrm{ng} / \mathrm{ml}$ & $18.8(8.0-48.8)$ & $3.8(1.0-5.3)$ & 0.0020 \\
\hline & ß-defensin 4 & $\mathrm{pg} / \mathrm{ml}$ & $2.0(2.0-603.3)$ & $3.0(2.0-110.0)$ & 0.6250 \\
\hline & SLPI & $\mathrm{ng} / \mathrm{ml}$ & $10.6(4.5-18.7)$ & $33.9(23.7-48.7)$ & 0.0010 \\
\hline & Elafin & $\mathrm{ng} / \mathrm{ml}$ & $4473.5(27.5-4906.2)$ & $6.5(2.1-10.5)$ & 0.0010 \\
\hline & Hnp-1-3 & $\mu \mathrm{g} / \mathrm{ml}$ & $21.4(8.8-250.0)$ & $0.2(0.007-1.3)$ & 0.0010 \\
\hline \multirow{9}{*}{ Chemokine } & IL-8 & $\mathrm{pg} / \mathrm{ml}$ & $30120.0(10846.6-76113.3)$ & $2.5(2.0-2.5)$ & 0.0020 \\
\hline & MCP-1 & $\mathrm{pg} / \mathrm{ml}$ & $170.0(4.7-2656.7)$ & $260.0(156.7-430.0)$ & 0.7646 \\
\hline & MCP-2 & $\mathrm{pg} / \mathrm{ml}$ & $2.0(2.0-36.7)$ & $110.0(73.3-120.0)$ & 0.0010 \\
\hline & MIP-1ß & $\mathrm{pg} / \mathrm{ml}$ & $20.0(2.0-706.7)$ & $53.3(43.3-93.3)$ & 0.4502 \\
\hline & MIP-3 $\alpha$ & $\mathrm{pg} / \mathrm{ml}$ & $900.0(126.7-7626.7)$ & $36.5(36.5-39.5)$ & 0.0010 \\
\hline & RANTES & $\mathrm{pg} / \mathrm{ml}$ & $10.0(1.0-116.7)$ & $32826.7(11133.3-47480.0)$ & 0.0010 \\
\hline & IP10 & $\mathrm{pg} / \mathrm{ml}$ & $606.7(290.0-4700.0)$ & $113.3(60.0-226.7)$ & 0.0010 \\
\hline & SDF-1ß & $\mathrm{pg} / \mathrm{ml}$ & $43.3(33.3-980.0)$ & $78.7(13.0-250.0)$ & 0.7646 \\
\hline & MIG & $\mathrm{pg} / \mathrm{ml}$ & $120.0(50.7-826.7)$ & $166.7(123.3-193.3)$ & 0.8948 \\
\hline \multirow{2}{*}{ Cell homing } & L-Selectin & $\mathrm{ng} / \mathrm{ml}$ & $0.6(0.1-11.2)$ & $103.8(73.4-136.0)$ & 0.0020 \\
\hline & P-Selectin & $\mathrm{ng} / \mathrm{ml}$ & $189.8(124.1-436.9)$ & $111.5(50.3-268.4)$ & 0.0010 \\
\hline \multirow{3}{*}{$\begin{array}{l}\text { Hematopoietic/ } \\
\text { Growth factor }\end{array}$} & IL-7 & $\mathrm{pg} / \mathrm{ml}$ & $9.0(7.0-93.3)$ & $13.5(4.0-55.7)$ & 0.7480 \\
\hline & GCSF & $\mathrm{pg} / \mathrm{ml}$ & $2008.3(506.7-7650.0)$ & $24.0(1.5-107.2)$ & 0.0020 \\
\hline & GM-CSF & $\mathrm{pg} / \mathrm{ml}$ & $7.3(2.0-26.7)$ & $86.7(48.7-103.3)$ & 0.0010 \\
\hline
\end{tabular}




\begin{tabular}{|c|c|c|c|c|c|}
\hline & TGF- $\beta$ & $\mathrm{pg} / \mathrm{ml}$ & $313.3(33.3-6130.0)$ & $126.7(32.7-183.3)$ & 0.0146 \\
\hline \multirow{6}{*}{ Antibody } & $\lg \mathrm{G} 1$ & $\mu \mathrm{g} / \mathrm{ml}$ & $46.8(14.1-119)$ & $10138.0(5491.9-14248.4)$ & 0.0039 \\
\hline & $\lg G 2$ & $\mu \mathrm{g} / \mathrm{ml}$ & $80.1(38.9-214.4)$ & $11272(6433.5-16170.0)$ & 0.0039 \\
\hline & $\lg \mathrm{lg} 3$ & $\mu \mathrm{g} / \mathrm{ml}$ & $1.7(0.2-10.9)$ & $646.4(266.6-1399.5)$ & 0.0039 \\
\hline & $\operatorname{lgG} 4$ & $\mu \mathrm{g} / \mathrm{ml}$ & $1.2(0.0-2.9)$ & $332.6(6-855.2)$ & 0.0078 \\
\hline & $\lg A$ & $\mu \mathrm{g} / \mathrm{ml}$ & $29.6(8.2-113.3)$ & $1427.7(628.4-2674.6)$ & 0.0039 \\
\hline & $\lg M$ & $\mu \mathrm{g} / \mathrm{ml}$ & $1.7(0.5-91.6)$ & $2108.2(1743.4-2960.6)$ & 0.0039 \\
\hline
\end{tabular}

Wilcoxon matched-pairs signed rank Test applied to values recorded for study subjects at visit 1 with $p$ values $<0.05$ considered to be significant 
Figure 1: Illustration of the timeline for study visits with a list of the localised analyte changes occurring in the mucosal compartment. Phases of the menstrual cycle were specified for volunteers as the number of days since their last menstrual period where day 1 coincided with the first day of their menses. Samples were collected during three scheduled visits coinciding with days 5-10 (end of menstruation; follicular phase), days 14-16 (ovulation), and days 19-24 (luteal phase). More analyte fluctuations were recorded in study subjects over the time points that were investigated in the mucosal compartment compared to the serum compartment.

\section{$178 \times 142 \mathrm{~mm}(300 \times 300 \mathrm{DPI})$}



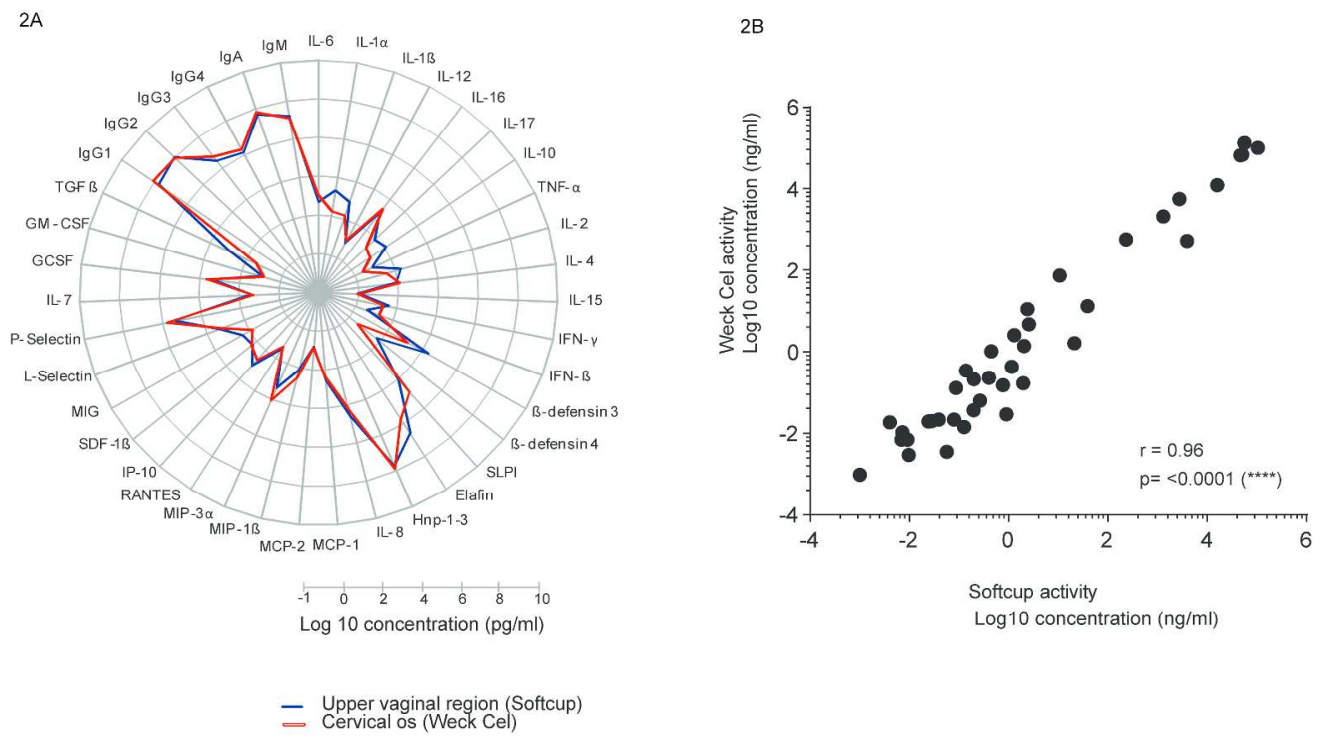

Figure 2A-B: Analysis of the secreted immunoproteome in the female genital tract. A) Sampling with Softcup and Weck Cel sampling techniques reveal similar analyte signatures at visit 1 (corresponding to days 5-10 of the menstrual cycle) in the vaginal and cervical os of 12 healthy women aged $18-45$ years. Points represent mean analyte concentration $(\mathrm{pg} / \mathrm{ml})$ of three experimental replicates. B) Comparison of 39 analyte concentrations (activity; $\mathrm{ng} / \mathrm{ml}$ ) in matched vaginal and cervical os samples collected from 12 women by Spearman rank correlation. Concentrations shown as Log 10 values in $\mathrm{ng} / \mathrm{ml}$. $\mathrm{p}=<0.0001 .95 \%$ confidence interval $=0.9184-0.9781$.

$283 \times 157 \mathrm{~mm}(300 \times 300 \mathrm{DPI})$ 
3

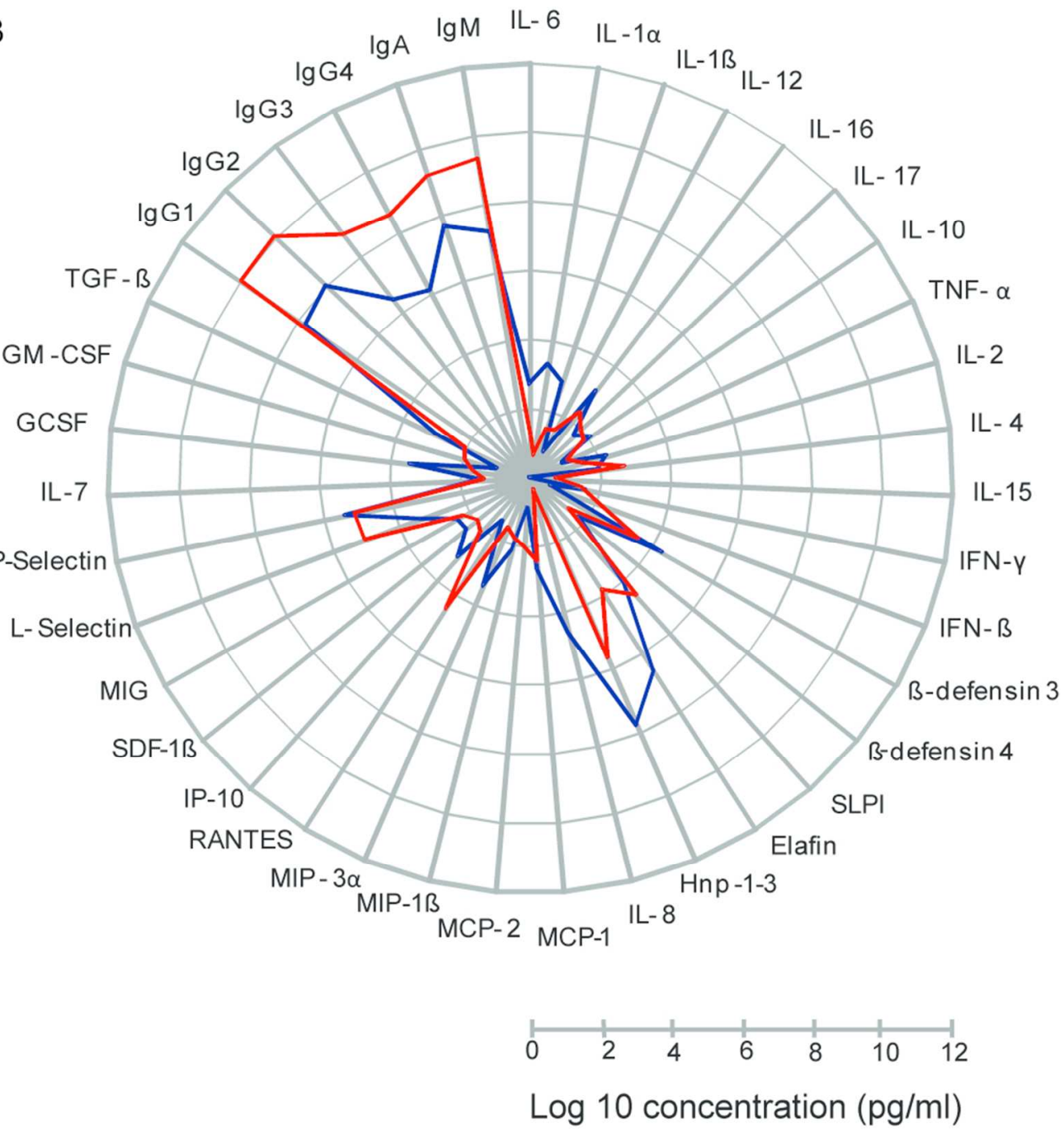

— Upper Vaginal region (Softcup)
Serum

$86 \times 102 \mathrm{~mm}(300 \times 300 \mathrm{DPI})$ 
1

2

3

4

5

6

7

8

9

10

11

12

13

14

15

16

17

18

19

20

21

22

23

24

25

26

27

28

29

30

31

32

33

34

35

36

37

38

39

40

41

42

43

44

45

46

47

48

49

50

51

52

53

54

55

56

57

58

59

60
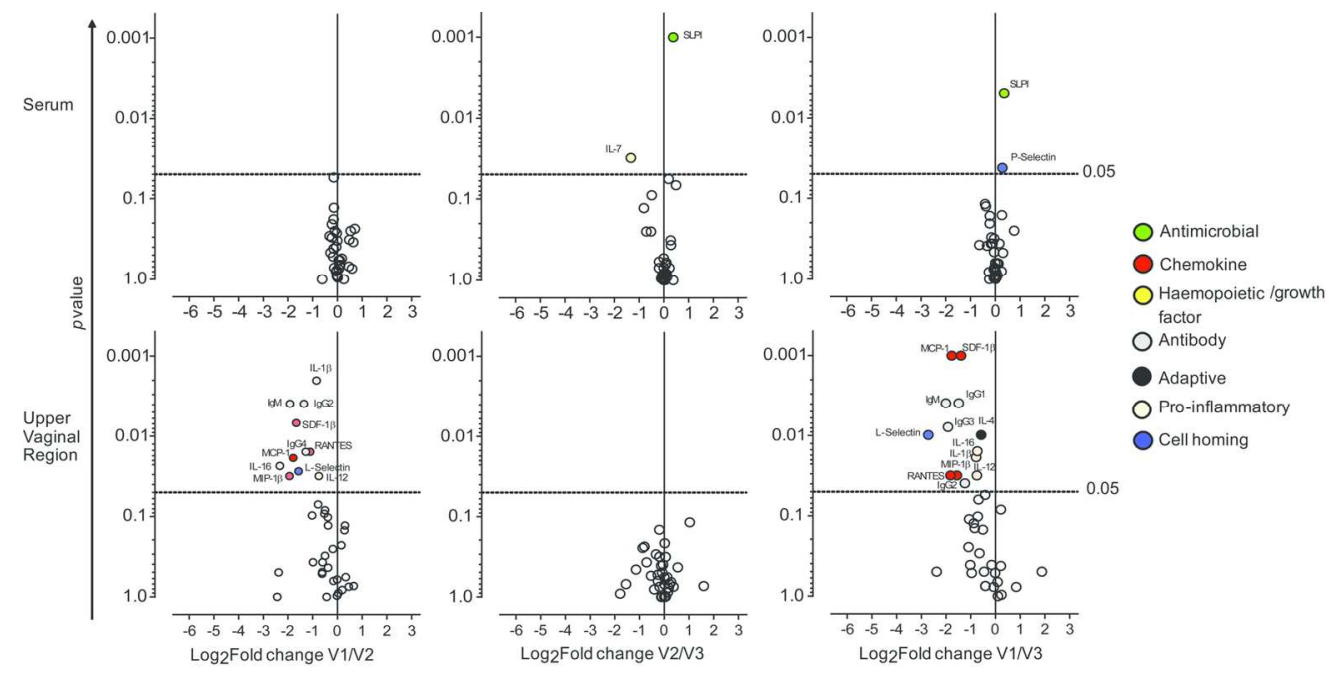

Figure 4: More analyte fluctuations observed across the menstrual cycle in the vaginal compartment compared to the serum compartment. Vertical lines represent the points where no change in analyte concentration occurred. Horizontal lines indicate the points where significance is achieved. $p$-values $<0.05$ were considered to be significant.

$151 \times 76 \mathrm{~mm}(300 \times 300 \mathrm{DPI})$ 


\section{Supplementary material}

Table 1: Median analyte concentrations in the mucosal sub-compartments in the follicular phase of the menstrual cycle

\begin{tabular}{|c|c|c|c|c|c|}
\hline \multirow[t]{2}{*}{$\begin{array}{l}\text { Functional } \\
\text { classification }\end{array}$} & \multirow[t]{2}{*}{ Analyte } & \multirow[t]{2}{*}{ Unit } & \multirow{2}{*}{$\begin{array}{l}\text { Cervicovaginal } \\
\text { region (Softcup) } \\
\text { median (range) }\end{array}$} & \multirow{2}{*}{$\begin{array}{l}\text { Endocervical region } \\
\text { (Weck Cel) } \\
\text { median (range) }\end{array}$} & \multirow[t]{2}{*}{$p$ value } \\
\hline & & & & & \\
\hline \multirow{7}{*}{ Pro-inflammatory } & IL-6 & $\mathrm{pg} / \mathrm{ml}$ & $326.7(2.0-2300)$ & $713.3(33.3-2490.0)$ & 0.0137 \\
\hline & IL-1a & $\mathrm{pg} / \mathrm{ml}$ & $993.3(556.7-11943.3)$ & $98.3(40.0-640.0)$ & 0.0005 \\
\hline & IL-1ß & $\mathrm{pg} / \mathrm{ml}$ & $313.3(40.0-3300.0)$ & $83.3(16.7-473.3)$ & 0.0049 \\
\hline & IL-12 & $\mathrm{pg} / \mathrm{ml}$ & $4.7(2.0-20.0)$ & $10.5(9.0-12.0)$ & 0.0586 \\
\hline & IL-16 & $\mathrm{pg} / \mathrm{ml}$ & $48.3(17.0-10683.3)$ & $2050(73.3-2050.0)$ & 0.1514 \\
\hline & IL-17 & $\mathrm{pg} / \mathrm{ml}$ & $35.0(35.0-290.0)$ & $25.0(5.3-30.0)$ & 0.0010 \\
\hline & TNF- $\alpha$ & $\mathrm{pg} / \mathrm{ml}$ & $2.0(2.0-73.3)$ & $2.0(1.3-7.3)$ & 0.6250 \\
\hline Anti-inflammatory & IL-10 & $\mathrm{pg} / \mathrm{ml}$ & $138.7(6.0-244.0)$ & $19.0(4.0-21.3)$ & 0.0049 \\
\hline \multirow{4}{*}{ Adaptive } & IL-2 & $\mathrm{pg} / \mathrm{ml}$ & $180.0(20.0-356.7)$ & $36.7(3.7-80.0)$ & 0.0010 \\
\hline & IL-4 & $\mathrm{pg} / \mathrm{ml}$ & $41.2(10.0-280.0)$ & $117.0(80.7-186.7)$ & 0.2734 \\
\hline & IL-15 & $\mathrm{pg} / \mathrm{ml}$ & $1.0(1.0-1.0)$ & $1.0(0.7-1.0)$ & $>0.9999$ \\
\hline & IFN-y & $\mathrm{pg} / \mathrm{ml}$ & $19.0(17.0-110.0)$ & $19.0(14.0-50.0)$ & 0.4648 \\
\hline \multirow{6}{*}{ Antimicrobial } & IFN-ß & $\mathrm{pg} / \mathrm{ml}$ & $2.2(0.3-10.0)$ & $19.0(14.0-50.0)$ & 0.0005 \\
\hline & ß-defensin 3 & $\mathrm{ng} / \mathrm{ml}$ & $20.3(8.0-48.8)$ & $1.1(0.3-8.6)$ & 0.0010 \\
\hline & ß-defensin 4 & $\mathrm{pg} / \mathrm{ml}$ & $2.0(2.0-603.3)$ & $2.0(2.0-10.0)$ & $>0.9999$ \\
\hline & SLPI & $\mathrm{ng} / \mathrm{ml}$ & $10.7(4.5-18.7)$ & $68.0(33.9-151.8)$ & 0.0005 \\
\hline & Elafin & $\mathrm{ng} / \mathrm{ml}$ & $4424.9(27.5-4906.2)$ & $445.0(146.2-1351.8)$ & 0.0010 \\
\hline & Hnp-1-3 & $\mu \mathrm{g} / \mathrm{ml}$ & $22.3(8.8-250.0)$ & $28.5(40.72-285.6)$ & 0.8501 \\
\hline \multirow{9}{*}{ Chemokine } & $\mathrm{IL}-8$ & $\mathrm{ng} / \mathrm{ml}$ & $28.1(10.8-76.1)$ & $10.5(2.0-35.1)$ & 0.0029 \\
\hline & MCP-1 & $\mathrm{pg} / \mathrm{ml}$ & $108.3(4.6-2656.7)$ & $178.3(26.7-1053.3)$ & 0.9697 \\
\hline & MCP-2 & $\mathrm{pg} / \mathrm{ml}$ & $2.0(2.0-36.7)$ & $7.3(4.7-10.0)$ & 0.3145 \\
\hline & MIP-1ß & $\mathrm{pg} / \mathrm{ml}$ & $11.0(2.0-706.7)$ & $225(10.0-2166.7)$ & 0.1763 \\
\hline & MIP-3a & $\mathrm{pg} / \mathrm{ml}$ & $861.7(126.7-7626.7)$ & 9938.335 (97.0-20553.3) & 0.0010 \\
\hline & RANTES & $\mathrm{pg} / \mathrm{ml}$ & $10.0(1.0-116.7)$ & $15(0.0-73.3)$ & 0.4004 \\
\hline & IP10 & $\mathrm{pg} / \mathrm{ml}$ & $766.7(290.0-4700.0)$ & 321.7 (33.3-1453.3) & 0.0005 \\
\hline & SDF-1ß & $\mathrm{pg} / \mathrm{ml}$ & $48.3(33.3-980.0)$ & $156.7(10.7-920.0)$ & 0.5195 \\
\hline & MIG & $\mathrm{pg} / \mathrm{ml}$ & $125.0(50.7-826.7)$ & $27(10.7-920.0)$ & 0.0010 \\
\hline \multirow{2}{*}{ Cell homing } & L-Selectin & $\mathrm{ng} / \mathrm{ml}$ & $0.5(0.1-11.2)$ & $0.8(0.1-7.7)$ & 0.8984 \\
\hline & P-Selectin & $\mathrm{ng} / \mathrm{ml}$ & $200.7(124.0-436.9)$ & $543.9(201.2-1112.6)$ & 0.0005 \\
\hline Hematopoietic/ & IL-7 & $\mathrm{pg} / \mathrm{ml}$ & $9.0(7.0-93.3)$ & $20.0(4.7-33.3)$ & 0.8945 \\
\hline Growth factor & GCSF & $\mathrm{ng} / \mathrm{ml}$ & $1.9(0.5-7.7)$ & $4.2(0.1-14.1)$ & 0.0244 \\
\hline
\end{tabular}




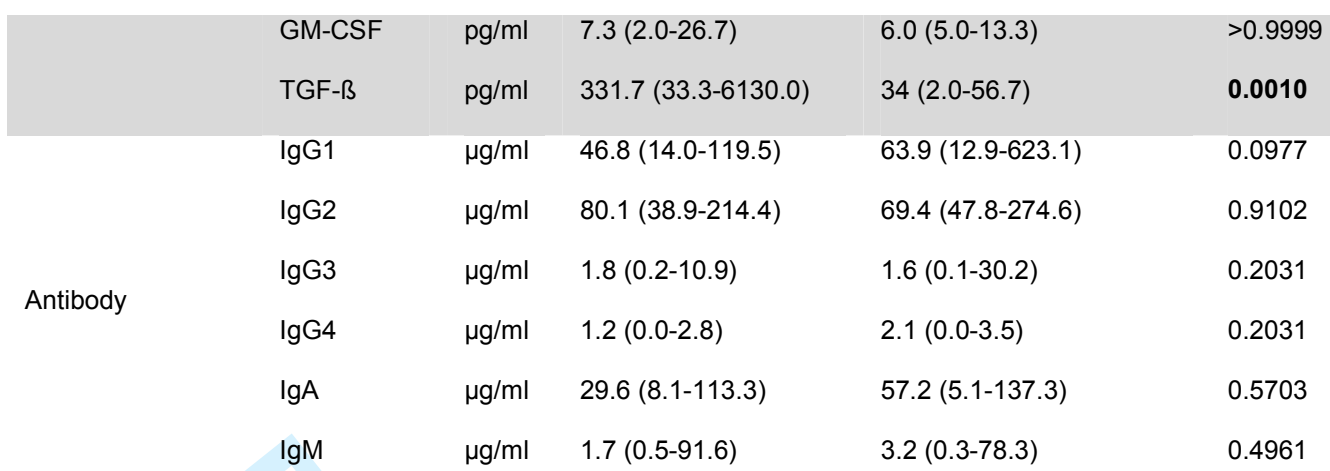

Wilcoxon matched-pairs signed rank Test applied to values recorded for study subjects at visit 1 with $p$ values $<0.05$ considered to be significant 


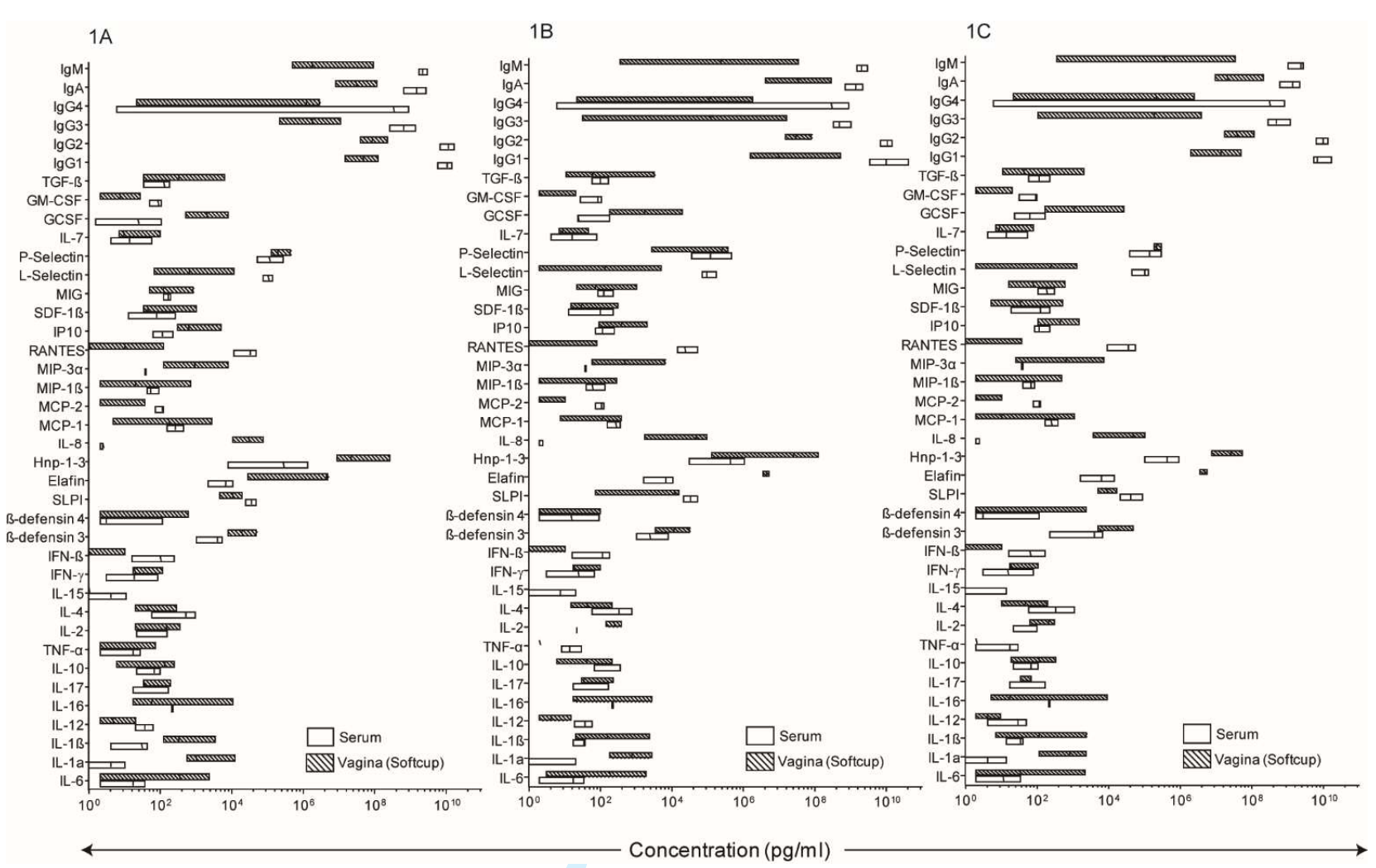



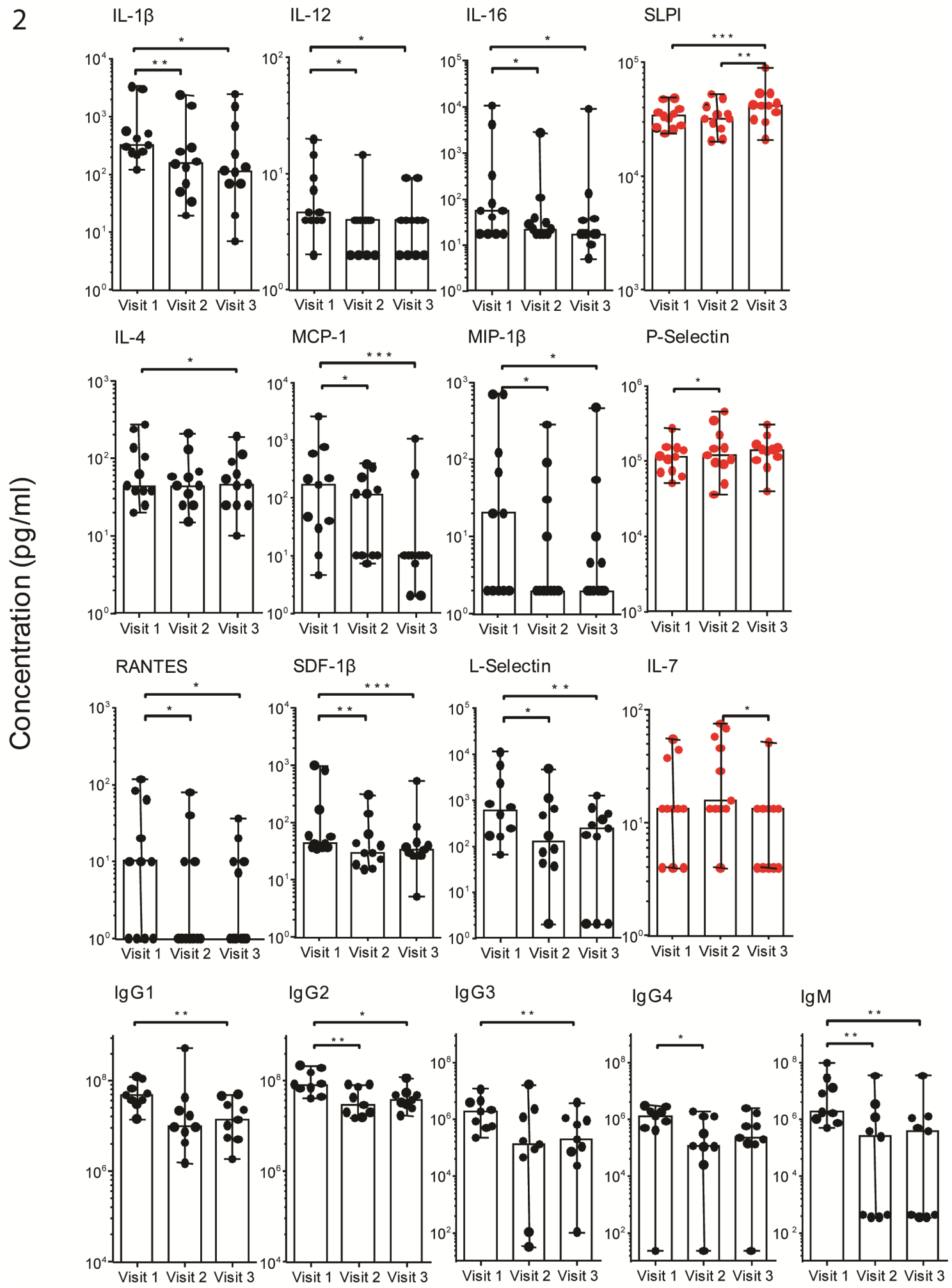

Page $\mathbf{4}$ of 5 
Supplementary Figure 1 A-C: Analyte signatures differ between peripheral (serum) and mucosal (Softcup) compartments across the menstrual cycle. Floating bars show maximum and minimum values recorded for 39 analytes in both compartments with a line at the median for samples collected from study participants at A) visit 1; days 5-10, B) visit 2; days 14-16, and C) visit 3; days 19-24. Data shown for three experimental replicates.

Supplementary Figure 2: More analyte fluctuations were observed in samples collected from the vaginal compartment $(\bullet)$ across the menstrual cycle compared to matched samples collected from the serum compartment $(\bullet)$. Scatter dots are representative of three experimental replicates with bars and lines showing median values and range. $p$-values $<0.05$ were considered to be significant. 
